\title{
Stress-Strain Behavior of Perfluorosulfonic Acid Membranes at Various Temperatures and Humidities: Experiments and Phenomenological Modeling
}

\author{
Ahmet Kusoglu \\ University of Delaware \\ Yaliang Tang \\ University of Delaware \\ Michael Santare \\ University of Delaware \\ Anette M. Karlsson \\ Cleveland State University, a.karlsson@csuohio.edu \\ Simon Cleghorn \\ Gore Fuel Cell Technologies

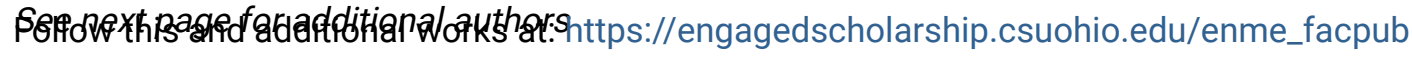 \\ Part of the Mechanical Engineering Commons, and the Membrane Science Commons \\ How does access to this work benefit you? Let us know!
}

Original Citation

Kusoglu, A., Tang, Y., Santare, M. H., 2009, "Stress-Strain Behavior of Perfluorosulfonic Acid Membranes at various Temperatures and Humidities: Experiments and Phenomenological Modeling," Journal of Fuel Cell Science and Technology, 6(1) pp. 011012.

This Article is brought to you for free and open access by the Mechanical Engineering Department at EngagedScholarship@CSU. It has been accepted for inclusion in Mechanical Engineering Faculty Publications by an authorized administrator of EngagedScholarship@CSU. For more information, please contact library.es@csuohio.edu. 


\section{Authors}

Ahmet Kusoglu, Yaliang Tang, Michael Santare, Anette M. Karlsson, Simon Cleghorn, and William B. Johnson 


\section{Stress-Strain Behavior of Perfluorosulfonic Acid Membranes at Various Temperatures and Humidities: Experiments and Phenomenological Modeling}

Department of Mechanical Engineering, University of Delaware, Newark, DE 19716

\author{
Simon Cleghorn \\ William B. Johnson \\ Gore Fuel Cell Technologies, \\ 201 Airport Road, \\ P.0. Box 1488 , \\ Elkton, MD 21922-1488
}

The constitutive response of perfluorinated sulfonic acid (PFSA) membranes based on tensile testing is investigated, and a phenomenological constitutive model for the elastoplastic flow behavior as a function of temperature and humidity is proposed. To this end, the G'Sell-Jonas (1979, "Determination of the Plastic Behavior of Solid Polymers at Constant True Strain Rate," J. Mater. Sci., 14, pp. 583-591) constitutive model for semicrystalline polymers is extended by incorporating, in addition to temperature, relationships between the material constants of this model and the measured relative humidity. By matching the proposed constitutive model to the experimental stress-strain data, useful material constants are found. Furthermore, correlations between these material constants and Young's modulus and proportional limit stress are investigated. The influence of material orientation, inherited from processing conditions, on the stress-strain behavior is also studied. The proposed model can be used to approximate the mechanical behavior of PFSA membranes in numerical simulations of a fuel cell operation.

Keywords: Nafion ${ }^{\circledR} 112$ membrane, proton exchange membranes, mechanical properties, stress-strain behavior, temperature, humidity, elastoplastic flow

\section{Introduction}

The mechanical properties and the hygrothermal behavior of the perfluorinated sulfonic acid (PFSA) membranes under different environmental conditions are of interest because of their important role as a proton exchange membrane (PEM) in fuel cell applications. PFSA membranes are widely used in PEM fuel cells as an electrolyte between the anode and cathode to provide a conductive path for proton transport [1-4]. The good electrochemical and thermomechanical stability of PFSA polymers, along with the high proton conductivity, makes them an ideal choice to use as a PEM $[1,3,5]$. PFSA is a fluoropolymer, which has a semicrystalline structure, consisting of a polytetrafluoroethylene (PTFE) backbone with side chains attached to the sulfonic acid groups (Fig. 1) [5]. Sulfonic acid groups tend to hydrate with water due to their hydrophilicity and therefore play a key role in ion transport $[5,6]$. The most commonly used commercially available PFSA based material is a Nafion ${ }^{\circledR 2}$ membrane produced by EI DuPont ${ }^{3}$ De Nemours and Company. The Nafion ${ }^{(8)}$ polymer is classified by its thickness and equivalent weight (EW), the number of grams of dry polymer per mole of sulfonic acid groups when the material is in the acid form [5]. For example a Nafion ${ }^{\circledR}$ 112 membrane refers to a membrane thickness, of 2 mil, i.e., $50.8 \mu \mathrm{m}$, and $\mathrm{EW}=1100$.

A range of failure mechanisms in the PEM, based on both chemical degradation and mechanical damage, eventually reduce

\footnotetext{
${ }^{1}$ Corresponding author.

${ }^{2}$ Nafion ${ }^{B}$ is a registered trademark of EI DuPont De Nemours and Company.

${ }^{3}$ DuPont $^{\mathrm{TM}}$ is a registered trademark of EI du Pont de Nemours and Company.
}

the performance and operating lifetime of the cell [1,7-11]. During the operation of the fuel cell, membrane temperatures are around $70-90^{\circ} \mathrm{C}$, and the membrane is highly humidified. These conditions cause a hygrothermal expansion of the membrane, which gives rise to stresses that play an important role in failures of PEM fuel cells [12-18]. Based on the durability testing of PEM fuel cell systems, several authors $[1,2,8,9,17,19]$ reported the importance of the mechanical properties of a membrane on the life of a cell. Therefore, in order to develop effective strategies to improve durability, it is essential to characterize the mechanical properties of these membranes at different temperatures and humidities.

It is well documented that humidity and temperature affect the material properties and the deformation behavior of polymers: Several studies regarding the deformation behavior of semicrystalline polymers, including fluoropolymers such as PTFE [20-22], as well as studies on the influence of temperature and/or humidity on the mechanical properties of Nafion ${ }^{\circledR}$ polymer membranes, have been published [14,17,18,23-27]. However, to the knowledge of the authors, only a limited number of studies related to the stress-strain behavior of PFSA membranes are available in the open literature $[17,18,23,26,27]$. Also, the plastic deformation behavior of PFSA membranes at different temperatures and humidities has not been investigated to any great extent. Kawano et al. [27] studied the stress-strain behavior of a Nafion ${ }^{\circledR}$ membrane in acid and various forms of salt using a dynamical mechanical analysis. They found a decrease in the initial slope of the loaddisplacement curves with increasing water content. Liu et al. [26] examined the tensile loading and stress-relaxation behavior of Nafion ${ }^{\circledR}$ membranes, considering the effect of strain rate, molecular weight, counterion type, and the presence of organic fillers. 


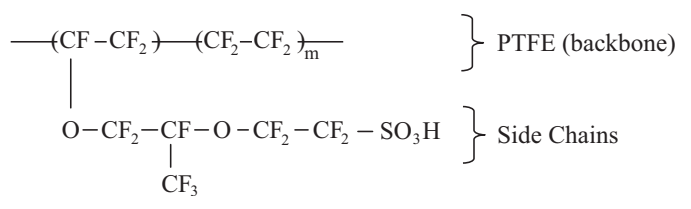

Fig. 1 Chemical structure of the Nafion ${ }^{\circledR}$ membrane

Solasi et al. [18] investigated the effect of temperature and humidity on the tensile stress-strain behavior of Nafion ${ }^{\circledR} 111$ membranes.

We have previously presented experimental investigations of Nafion ${ }^{\circledR} 112$ membranes [23], where the classical material properties-Young's modulus, proportional limit strength, break stress, and break strain-were explored as functions of temperature and relative humidity based on the stress-strain curves through tensile testing conducted at a constant strain rate. In this study, we will present the experimental true stress-true strain curves for the Nafion ${ }^{\circledR} 112$ membranes and discuss the main features of the elastoplastic behavior through a range of temperatures and humidities. Then, we propose a phenomenological constitutive model that describes the tensile stress-strain behavior of the PFSA membranes. Although phenomenological constitutive models have previously been proposed to describe the stress-strain behavior of polymers at various temperatures [28,29], a model that takes into account the effect of humidity has not previously been developed.

Our aim in this study is to describe, with a single equation, the elastoplastic true stress-true strain behavior of PFSA membranes through a range of environmental conditions. The purpose of this study is not to produce just an accurate curve fit, but rather to develop a model where each material constant has a physical meaning. This model can help to elucidate the influence of humidity on the stress-strain behavior of these materials. Such a model is essential for a numerical simulation of fuel cell membranes in situ. In addition, it provides a basis for further investigation into the mechanical behavior of PFSA membranes. A complete treatment of the subject and the existing challenges requires a comprehensive interdisciplinary study, including issues related to the strain-rate dependence, morphological changes, electrochemical interactions, and polymer chain configurations, which are all beyond the scope of this study.

\section{Experiments}

The influence of temperature and humidity on the mechanical properties of PFSA membranes has been reported previously by Tang et al. [23] and is summarized here. A Nafion ${ }^{\circledR} 112$ membrane, a commercially available PFSA membrane (by Dupont ${ }^{\mathrm{TM}}$ ), was used for all of the experiments. The membranes were provided by DuPont (EI du Pont de Nemours and Company). No specific information about the processing or extrusion was provided. Membrane mechanical properties were measured under 16 controlled environments; four temperatures $\left(25^{\circ} \mathrm{C}, 45^{\circ} \mathrm{C}, 65^{\circ} \mathrm{C}\right.$, and $85^{\circ} \mathrm{C}$ ), and four relative humidities $(30 \%, 50 \%, 70 \%$, and 90\%) [23].

Tensile tests of the membrane were conducted on an MTS Alliance $^{\mathrm{TM}} \mathrm{RT} / 5$ material testing system with an ESPEC customdesigned environmental chamber. Material samples in both transverse (TD) and machine directions (MD) were tested to investigate any effect that the extrusion process has on the mechanical properties. All tests were conducted at a constant crosshead displacement rate of $0.2 \mathrm{~mm} / \mathrm{min}$. Further details pertaining to the experimental procedure may be found in Tang et al. [23]. For each temperature-humidity combination, the average of the engineering stress-strain data obtained from five specimens was determined.

For all tensile tests conducted, we observed a uniform deformation in the membrane without any discernible necking (Fig. 2) up

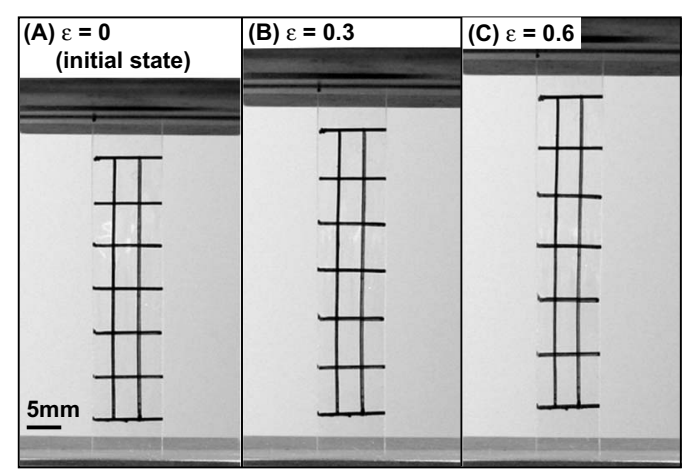

Fig. 2 Deformation of the Nafion ${ }^{\circledR} 112$ membrane during a uniaxial tension test conducted at $25^{\circ} \mathrm{C}$ and $50 \%$ relative humidity, shown with grids, for three strain values: (a) $\varepsilon=0$ (initial state), (b) $\varepsilon=0.3$, and (c) $\varepsilon=0.6$

to strains as high as $100 \%$ or more. ${ }^{4}$ The figure shows the deformation of grids-drawn on the unstretched membrane before testing-during a typical tensile test for selected stretch ratios $(\mathrm{mm} / \mathrm{mm})$. This observation justifies the use of true stress-true strain from the engineering data. Therefore, we will convert the data to true stress-true strain using the following relations [30]:

$$
\begin{gathered}
\sigma=\sigma^{\mathrm{eng}}\left(1+\varepsilon^{\mathrm{eng}}\right) \\
\varepsilon=\ln \left(1+\varepsilon^{\mathrm{eng}}\right)
\end{gathered}
$$

where $\sigma^{\text {eng }}$ and $\varepsilon^{\text {eng }}$ are the experimentally measured engineering stress $(\mathrm{MPa})$ and strain $(\mathrm{mm} / \mathrm{mm})$ values, respectively. ${ }^{5}$ True stress-strain, rather than engineering stress-strain, should be used to characterize the mechanical response of polymers at large deformations (including the plastic instability) since this is a better estimate of the actual state of stress in the material than engineering stress-strain [30]. (As can be seen in Eqs. (1a) and (1b) at 10\% engineering strain, the true stress is $10 \%$ higher than the engineering stress; thus for strains higher than approximately $10 \%$, the use of Eqs. (1a) and ( $1 b)$ is particularly important.) The resulting true stress-true strain curves are shown in Figs. 3 and 4 for the machine and transverse directions.

\section{Development of a Phenomenological Constitutive Model}

Phenomenological constitutive models can be developed by simply fitting the experimental stress-strain data to variable functions without consideration of the thermodynamic activation of the molecules [29]. G'Sell and Jonas [28] developed an empirical constitutive relation, which captures the viscoelasticity and viscoplasticity behaviors of polyvinyl chloride and high density polyethylene observed experimentally. Due to its simplicity and ability to capture the major features of the stress-strain behavior of the PFSA membrane, we chose to base our constitutive model on the G'Sell-Jonas approach. In this model, the stress is expressed as a function of equivalent strain, $\varepsilon$, and equivalent strain rate, $\dot{\varepsilon}$; according to

\footnotetext{
${ }^{4}$ The use of an extensometer to calibrate the crosshead displacement showed consistent measurements between the crosshead displacement and the material deformation. Therefore during tensile testing the crosshead displacement was taken as the actual displacement in the specimen.

${ }^{5}$ The engineering stress is the measured force divided by the original cross sectional area, the engineering strain is the change in length divided by the original length or the gauge length. For the specimens tested, the cross sectional area is determined from the width and thickness of the membrane.
} 

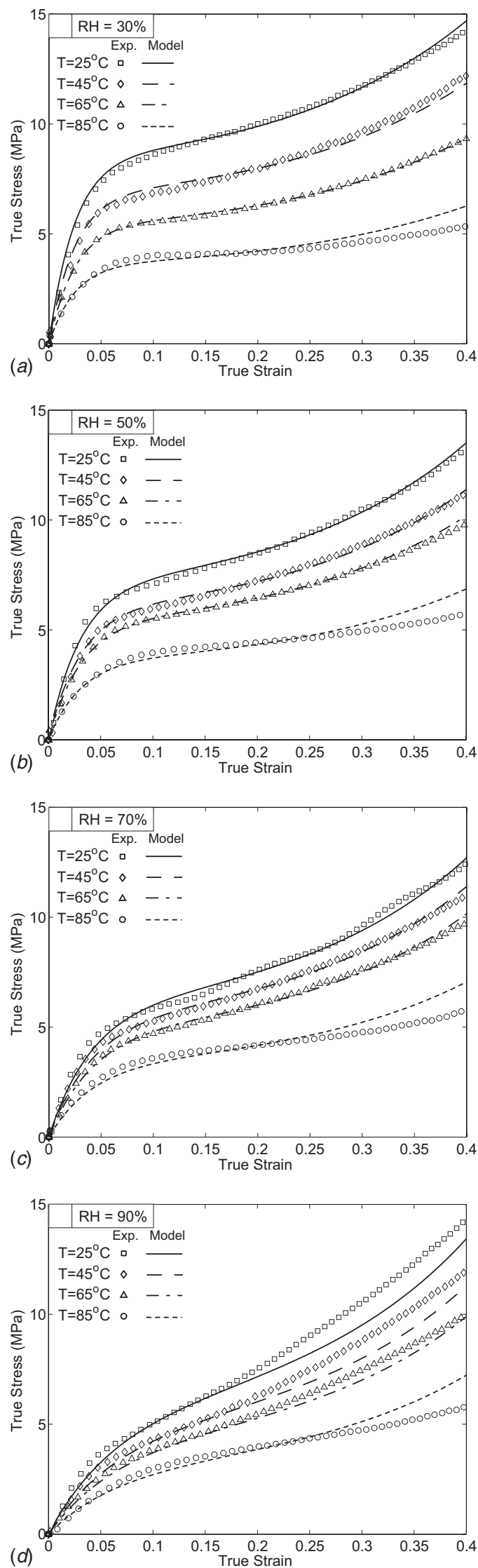

Fig. 3 The experimental true stress-strain data (markers) obtained for the machine direction, plotted with the proposed constitutive model (solid lines) at four temperature values for (a) $30 \%$, (b) $50 \%$, (c) $70 \%$, and (d) $90 \%$ relative humidities
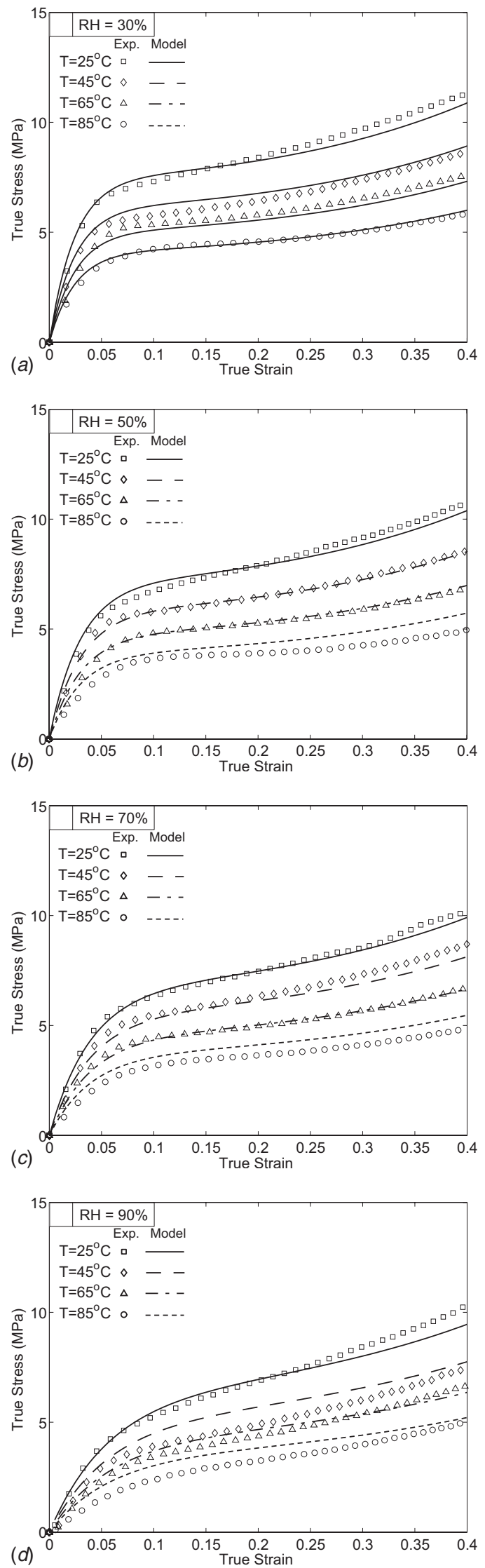

Fig. 4 The experimental true stress-strain data (markers) obtained for the transverse direction plotted with the constitutive model (solid lines) at four temperatures for (a) $\mathbf{3 0 \%}$, (b) $\mathbf{5 0 \%}$, (c) $70 \%$, and (d) $90 \%$ relative humidities 


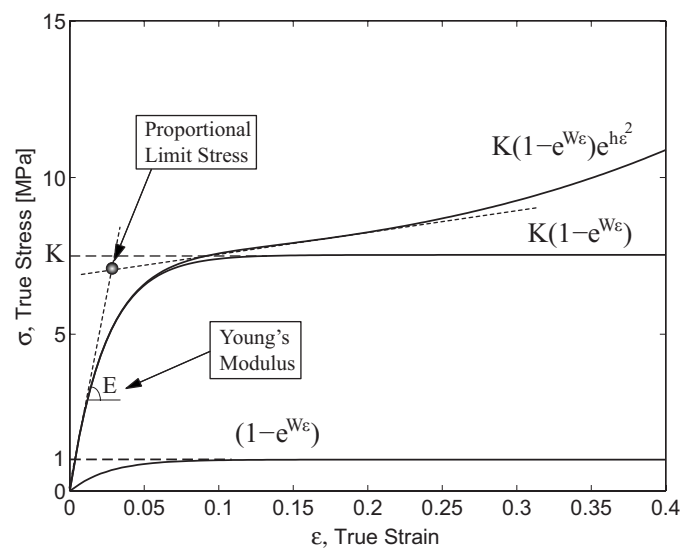

Fig. 5 Contribution of the terms in the constitutive model (Eq. (3)) to the stress-strain behavior of the material. In the plot, the following values have been used: $K=7.53, W=41$, and $h=2.3$.

$$
(\varepsilon, T)=K\left(1-e^{-W \varepsilon}\right)(\dot{\varepsilon})^{m} e^{h \varepsilon^{2}}
$$

where $W, m$, and $h$ are the material constants used to characterize the nonlinear stiffness behavior, strain-rate sensitivity, and strain hardening behavior, respectively.

Furthermore, the effect of temperature is implemented in the original model using the relationship $K=K_{0} e^{\alpha / T}$, where $\alpha$ characterizes the temperature dependence on the absolute temperature, $T$ [28]. The parameter $K$ characterizes the onset of the initial nonlinearity of the constitutive response (see Fig. 5) and has the units of stress. Thus, we will refer to $K$ as the "characteristic stress." Furthermore, we note that $K$ is related to the proportional limit stress (defined in Fig. 5), which is a useful way of representing the yield strength in polymers.

Thus, in the G'Sell-Jonas model, the temperature dependence of the flow behavior is described by the $e^{\alpha / T}$ term; the initial nonlinear behavior is described by the $\left(1-e^{-W \varepsilon}\right)$ term; and the viscous behavior and plastic strain hardening are expressed with the $\dot{\varepsilon}^{m}$ and $e^{h \varepsilon^{2}}$ terms, respectively $[28,29]$. The contribution of selected terms in Eq. (2) to the total constitutive behavior of the material is depicted in Fig. 5, with the representation of each function in an example stress-strain curve. The individual effects of each of the material constants, $K, W$, and $h$, on the stress-strain curves are demonstrated in the figure.

In this study, since the tensile tests were conducted at a constant crosshead displacement rate, we will rewrite Eq. (2) for the constant strain rate. More importantly, we will expand the material parameters to include not only temperature dependence but also humidity dependence. (The expansion of this new relationship to include strain-rate behavior can be conducted when additional experimental data become available.) In addition, temperature dependence is included implicitly in the characteristic stress, $K$, and we assume that humidity dependence is included in all terms. Thus

$$
(\varepsilon, T, H)=K(T, H)\left(1-e^{-W(H) \varepsilon}\right) e^{h(H) \varepsilon^{2}}
$$

where $K(T, H), W(H)$, and $h(H)$ are the material parameters expressed as functions of temperature and/or humidity, and $H$ is the relative humidity $(\% \mathrm{RH})$. Through trial and error, we were able to determine that introducing additional parameters for the temperature dependence of $W$ and $h$ has negligible effects on the resulting constitutive behavior. Thus, since the temperature dependence for a given humidity is defined within $K$ by the virtue of the model, we will assume that the other material parameters only change with humidity.

The water content in PFSA membranes has been estimated in experimental studies for various relative humidities, and mathematical models have been proposed to describe the water content as a function of relative humidity [31,32]. However, the relationships among the water content, temperature, and humidity have not yet been fully established. Therefore, considering the ease of measuring relative humidity rather than finding the water content, relative humidity is used in this study as the variable to represent the water content. Thus, we will develop such a model by incorporating empirical relations between humidity and the temperature-dependent material constants in the G'Sell-Jonas [28] constitutive model for semicrystalline polymers.

\section{Fitting of Experimental Data}

The simple constitutive model given in Eq. (3) will now be fitted to the experimentally obtained stress-strain curves. For each temperature-humidity combination, a least squares approach is used to determine an independent set of material parameters for Eq. (3). The method of "least squares" minimizes the square of the difference between the experimental stress values and the calculated stress values. The residual function, $R$, which is to be minimized, is

$$
R=\sum_{\varepsilon}\left(\exp (\varepsilon)-{ }_{\text {num }}(\varepsilon ; K, W, h)\right)^{2}
$$

where the stresses obtained numerically from the model, num, are defined as a function of the true strain and the material parameters, and the experimental stresses, exp, are a function of only the true strain. The function $R$ is calculated over the strain range from 0 to 0.4 since at larger strains deviation from the experimental values increases.

Once a best-fit set of the parameters (minimum $R$ ) is determined for each test condition, functional relationships between the material parameters and the temperature and humidity can be developed. In the following, each material constant found through this optimization is attributed a physical role in explaining the relationships among the humidity, temperature, and elastoplastic flow behavior.

\section{Results}

5.1 Modified G'Sell-Jonas Model. Values of the material properties $K, W$, and $h$ at the investigated relative humidities are obtained for the two main in-plane orientations (TD and MD) and are shown in Table 1 . The values in Table 1 are obtained by finding the best-fit values for the material constants at each temperature-humidity combination. We will now develop functions that describe the individual properties as functions of temperature and humidity.

We observe that the nonlinear stiffness parameter, $W$, decreases linearly with relative humidity for both machine and transverse directions and can therefore be written as an affine function with two constants,

$$
W(H)=W_{0}(1-\varpi H)
$$

where $W_{0}$ is the material constant from the original model (see Eq. (3)) and $\varpi(1 / \% \mathrm{RH})$ is the new material constant introduced here to include humidity dependence. These two parameters are found to be virtually identical for both orientations, with a difference of less than $1 \%$. Therefore, we concluded that these values are orientation independent, and the average values for $W_{0}$ and $\varpi$ are used for both TD and MD (see Table 2).

The plastic strain hardening parameter, $h$, was found to be essentially constant in the transverse direction. However, in the machine direction, the strain hardening parameter increases monotonically with increasing humidity (Table 1$)$. Therefore, $h$ can be related to humidity as

$$
h(H)=h_{0}\left(1+h_{1} H\right)
$$

where $h_{0}$ is the strain hardening constant of the original model (see Eq. (3)) and $h_{1}$ is the new constant having a unit of $1 / \% \mathrm{RH}$, which can be attributed to the increase in hardening of the mem- 
Table 1 The best-fit values for $W$ and $h$ found at each relative humidity independent of the temperature and best-fit values for $K$ found at each temperature and relative humidity value for the machine direction (MD) and the transverse direction (TD)

\begin{tabular}{|c|c|c|c|c|c|c|}
\hline \multirow{2}{*}{$\begin{array}{l}\text { MD } \\
\% \text { RH }\end{array}$} & \multicolumn{4}{|c|}{$K(\mathrm{MPa})$} & \multirow[b]{2}{*}{$W$} & \multirow[b]{2}{*}{$h$} \\
\hline & $T=25^{\circ} \mathrm{C}$ & $T=45^{\circ} \mathrm{C}$ & $T=65^{\circ} \mathrm{C}$ & $T=85^{\circ} \mathrm{C}$ & & \\
\hline 30 & 8.67 & 7.00 & 5.51 & 3.70 & 41 & 3.3 \\
\hline 50 & 7.35 & 6.20 & 5.55 & 3.73 & 33 & 3.8 \\
\hline 70 & 6.39 & 5.73 & 5.10 & 3.55 & 25 & 4.3 \\
\hline 90 & 6.25 & 5.26 & 4.61 & 3.36 & 17 & 4.8 \\
\hline \multicolumn{7}{|l|}{ TD } \\
\hline 30 & 7.61 & 5.86 & 5.28 & 4.13 & 41 & 2.3 \\
\hline 50 & 7.32 & 5.89 & 4.73 & 3.47 & 33 & 2.3 \\
\hline 70 & 6.89 & 5.84 & 4.62 & 3.34 & 25 & 2.3 \\
\hline 90 & 6.55 & 4.70 & 4.16 & 3.02 & 17 & 2.3 \\
\hline
\end{tabular}

brane with increasing humidity. The best-fit values of $h_{0}$ and $h_{1}$ are displayed in Table 2.

Best-fit values of the characteristic stress, $K$ ( $K$ approximately characterizes the proportional limit), at each temperature-humidity condition are shown in Table 1 . The previously described exponential relationship between $K(\mathrm{MPa})$ and the temperature $T(\mathrm{~K})$ can be extended so as to include the relative humidity, $H[\% \mathrm{RH}]$, dependence, and the new functional relationship is proposed such that

$$
K(T, H)=K_{0} e^{-\alpha T-\beta H}
$$

where $K_{0}(\mathrm{MPa}), \alpha(1 / \mathrm{K})$, and $\beta(1 / \% \mathrm{RH})$ are physically based material constants. $\alpha$ and $\beta$ are the temperature and humidity coefficients, respectively, and they characterize the changes in the characteristic stresses due to temperature and humidity. A larger value indicates stronger dependence. However in order to fully understand the meaning of these constants, different materials should be tested for a comparison of their dependence on these environmental variables.

Equation (3) and the functional relationships for each material parameter (Eqs. (5)-(7)) describe the material behavior. Combining these into a single constitutive equation results in

$$
(\varepsilon, T, H)=K_{0} e^{-(\alpha T+\beta H)}\left(1-e^{-W_{0}(1-\varpi H) \varepsilon}\right) e^{h_{0}\left(1+h_{1} H\right) \varepsilon^{2}}
$$

In summary, in this proposed modified G'Sell-Jonas model, true stress, , is an explicit function of true strain, $\varepsilon$, absolute temperature, $T$, and percent relative humidity, $H$. Specific material constants for the Nafion ${ }^{\circledR} 112$ polymer in both machine and transverse directions are given in Table 2. The experimental stressstrain curves of the Nafion ${ }^{\circledR} 112$ polymer membrane are plotted with the data calculated from the proposed constitutive model for four temperature and four relative humidity values for the machine direction in Figs. 3(a) $-3(d)$ and the transverse direction in Figs. $4(a)-4(d)$.

5.2 Investigation of Material Constants. Two different material parameters can be used to characterize the stress at the onset of the strongly nonlinear portion of the stress-strain curve. The

Table 2 Best-fit material constants of the proposed constitu-

\begin{tabular}{|c|c|c|c|c|c|c|c|}
\hline & \multicolumn{3}{|c|}{ K } & \multicolumn{2}{|r|}{$W$} & \multicolumn{2}{|r|}{$h$} \\
\hline & $K_{0}$ & $\alpha$ & $\beta$ & $W_{0}$ & $\varpi$ & $h_{0}$ & $h_{1}$ \\
\hline Units & $\mathrm{MPa}$ & $1 / \mathrm{K}$ & $\% \mathrm{RH}$ & & $1 / \% \mathrm{RH}$ & & $1 / \% \mathrm{RH}$ \\
\hline MD & 200.015 & 0.0101 & 0.0048 & 53 & 0.0075 & 2.55 & 0.0098 \\
\hline TD & 155.549 & 0.0099 & 0.0023 & 53 & 0.0075 & 2.30 & 0 \\
\hline
\end{tabular}
tive model given for MD and TD first is the characteristic stress $K$, (given in Eq. (7), appearing in Eq. (3), and tabulated in Table 1), and the second is the proportional limit used in our previous paper [23]. The proportional limit is found according to the graphical definition described in Fig. 5. Although this graphical method is not the only way to quantify the bend in the stress-strain curve, we have found that this method is intuitive, repeatable, and relatively straightforward to apply.

In order to determine the relationship between the characteristic stress, $K$ (Table 1), and the proportional limit, $\quad p$ [23], these values are plotted against each other in Fig. 6 for each data point. The plot shows that $K$ is essentially proportional to the proportional limit regardless of the temperature and relative humidity point for both transverse and machine directions. Similarly, the nonlinear stiffness parameter, $W$ (Table 1), can be related to the stiffness-tostrength ratio of the material. Notice that at low strains, the slope of the stress-strain curve given in Eq. (2) leads to $E=\partial / \partial \varepsilon$ $\approx K W \approx{ }^{p} W$, suggesting that $W$ is roughly proportional to Young's modulus, $E$ [23], divided by the proportional limit, $p$ (Fig. 7). Thus, $W$ is proportional to the inverse of the strain at the proportional limit, $\varepsilon^{p}$. Although the data in Fig. 7 show some scatter, an approximate overall linear correlation can be observed for each humidity value.

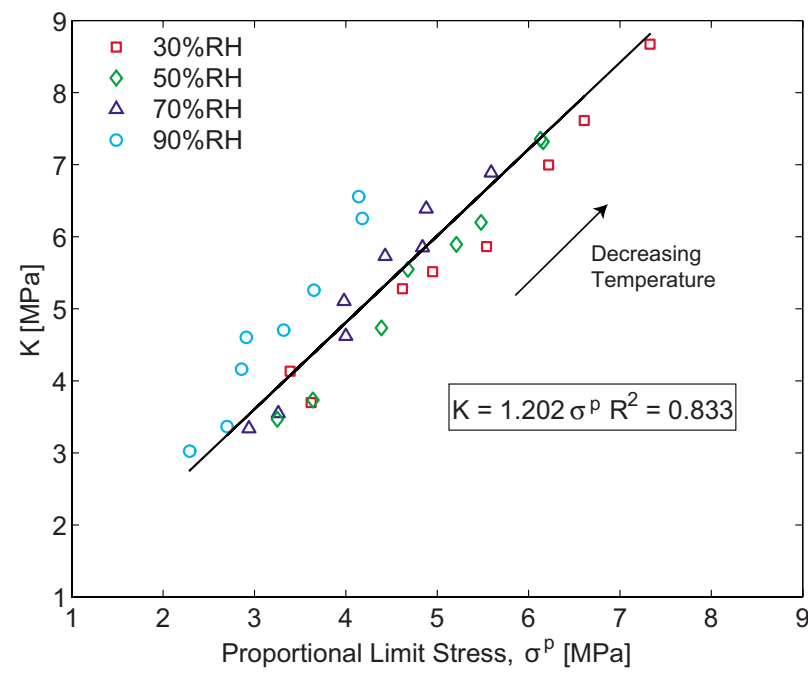

Fig. 6 The material constant, $K$ (Table 1), and the proportional limit, $\sigma^{p}[23]$, plotted at each temperature and relative humidity for both transverse and machine directions. The slope of the fitted line gives the constant $C_{1}$. 


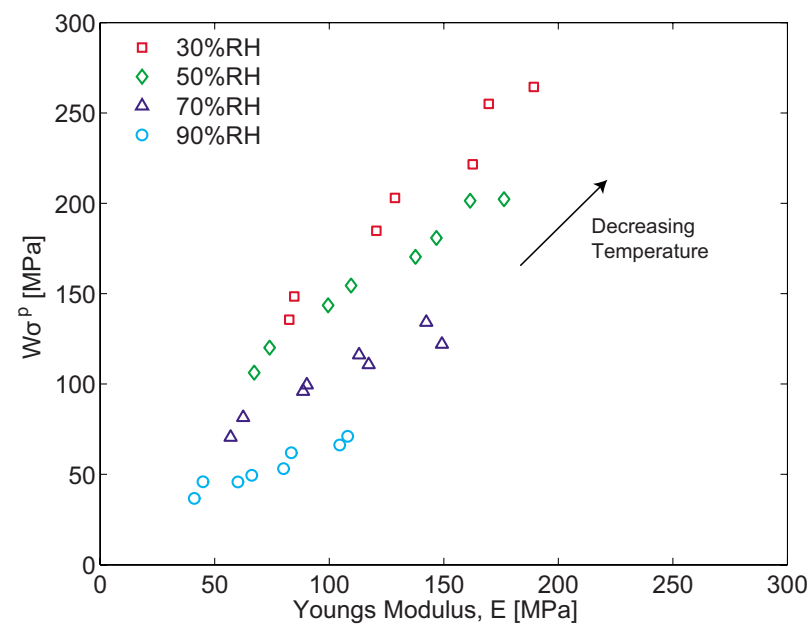

Fig. 7 The values of $W \sigma^{p}$ and $E$ [23] are plotted at each temperature and relative humidity. The slope of the fitted line represents the constant $C_{2}$.

\section{Discussion}

We see from the results that the nonlinear stiffness parameter (which can also be seen as the stiffness-to-strength ratio), $W$, decreases monotonically with increasing humidity for both loading directions, indicating that the elastic behavior of the material is affected by humidity in an essentially isotropic manner. Thus, the decrease in the stiffness with humidity seems to be independent of any alignment of the microstructure caused by the extrusion process used during manufacturing. A similar trend was also observed in the studies of Kawano et al. [27], where the initial slope of the stress-strain curves of the PFSA membrane decreases with increasing humidity.

The present study also shows that the characteristic stress, $K$, and therefore the proportional limit stress, $p$, decrease with both increasing temperature and increasing humidity. This phenomenon can be explained by the fact that at low strains, the elastic response is mainly dominated by the interaction between the aggregates [33]. Hence, the decrease in the elastic modulus at low strains with increasing humidity can be attributed to the plasticizing effect of water that results in an increased mobility of side chains [24,25,27]. Furthermore, the decrease in characteristic stress, $K$, at higher temperatures can be interpreted as a decrease in the initial slope of the stress-strain curves, which might be due to the enhanced chain mobility as a result of increased molecular kinetic energy [27].

Beyond the proportional limit, for strains larger than 0.15-0.20, significant strain hardening induces anisotropy (Figs. 3 and 4), presumably due to the alignment of the chains in the loading direction. Structural change in the PFSA membrane under uniaxial stretching can be explained by two simultaneous mechanisms [33,34]: (i) the rotation of large bundles (collection of elongated polymeric aggregates), which is the predominant structure at low strain levels, and (ii) the alignment of the aggregates within the bundles upon further stretching due to sliding or disentangling of the aggregates from each other. Therefore, based on this model, the strain hardening behavior of PFSA membranes at high strains may be attributed to the alignment of the polymeric aggregates.

The strain hardening parameter, $h$, does not change with humidity in the transverse direction $\left(h_{1}=0\right.$ in Eq. (6)). However, in the machine direction, $h$ increases linearly with humidity $\left(h_{1} \neq 0\right.$ in Eq. (6)), indicating not only that hardening is humidity dependent but also that this dependence changes with orientation. This orientation effect may be attributed to the alignment of the polymer chains during the extrusion processing of the ionomer membrane since extrusion can cause a microstructural orientation in the machine direction $[5,26]$.

At low strains, stresses decrease with increasing humidity. For higher strains $(>0.25-0.3)$, strain hardening becomes more pronounced at higher humidities in the machine direction. As a result, at high strains, the stress at high humidity (90\%) gets closer to that of low humidity. One explanation for these phenomena might be that the interactions among the growing ionic clusters at high humidities reduce the mobility of the chains [27], and it is suggested that these interactions are more pronounced beyond yielding and at higher strains [26]. Nevertheless, the influence of humidity on the hardening behavior of polymer membranes is rather complicated, and further studies are required to investigate the deformation behavior at a molecular level. Therefore, studying the swelling behavior of the membrane in terms of water content, by taking into account the morphological changes during the deformation, might help to understand the effect of water on the structure of PFSA membranes. This phenomenon is the subject of ongoing research.

The data used in the present study are based on an extensive experimentation of a single material, Nafion ${ }^{\circledR} 112$ membrane. Further tests for different materials should be conducted in order to gain a deeper understanding of the meaning of the material constants introduced. For example, a comparison of the constants $\beta$, $\omega$, and $h_{1}$ for different materials will help to explain how strongly the humidity affects the stress-strain behavior of the materials. The strain-rate sensitivity of this materials should also be considered, which requires time-dependent testing.

The accuracy of the proposed model decreases significantly for strain values larger than 0.3 , especially at elevated temperatures $\left(65-85^{\circ} \mathrm{C}\right)$ and at high relative humidity $(90 \% \mathrm{RH})$, where the experimental stresses are lower than the predicted (numerical) values. Although we successfully modeled the measured decrease in strength with increasing temperature and humidity, the influence of these two variables on the constitutive behavior was assumed to be independent. This may not be the case since at high temperatures (close to the glass transition temperature) the molecular relaxation mechanisms in the polymer are activated, and humidity can also play an important role in these mechanisms [24,35,36]. For example, although the glass transition temperature $\left(T_{g}\right)$ of Nafion ${ }^{\circledR}$ membranes has been found to be between $90^{\circ} \mathrm{C}$ and $115^{\circ} \mathrm{C}$, the plasticizing effect of water may reduce the $T_{g}$ at higher humidities $[24,35,36]$ since the absorption of water molecules by the ionic clusters increases the free volume, therefore enhancing the chain mobility [35]. Thus, when the membrane is humidified at elevated temperatures $\left(85^{\circ} \mathrm{C}\right)$, the combined effects of temperature and humidity might cause a further decrease in strength due to the interactions among different molecular relaxation mechanisms, which are not considered in this model.

The results presented in this paper have two main benefits for the study of the mechanical properties of PFSA membranes and for the design and development of new proton exchange membranes. First, due to its simplicity, the constitutive model will be a useful tool for the implementation of the material response in numerical models (i.e., finite element analysis). In addition, this study provides a basis for further investigation into the material characterization and the influence of humidity and temperature on the mechanical behavior of PFSA membranes. For instance, the observed increase in hardening at high humidities provides a motivation for studying the deformation of polymer chains at various water contents. Furthermore, since the temperature and humidity dependence of the material constants are given, the stress-strain behavior of these types of polymers can be studied by conducting a limited number of experiments instead of experiments at a wide temperature-humidity range as in Tang et al. [23]. 


\section{Concluding Remarks}

In this study, the true stress-true strain behavior of PFSA membranes is investigated based on experimental tensile tests of Nafion ${ }^{\circledR} 112$ membranes conducted at 16 temperature-humidity points with temperatures ranging from $25^{\circ} \mathrm{C}$ to $85^{\circ} \mathrm{C}$ and relative humidities ranging from $30 \% \mathrm{RH}$ to $90 \% \mathrm{RH}$ in the machine and transverse directions [23]. Based on these experimental data, a temperature and humidity dependent phenomenological constitutive model was developed for the membranes (Eq. (8)). Empirical relations for the required material parameters, as a function of temperature and humidity, were determined using a modified version of a constitutive equation developed by G'Sell and Jonas (Eq. (8)). Based on the observed relationships among the material constants identified in the modified G'Sell-Jonas model and the traditional mechanical properties (elastic modulus and proportional limit stress), the terms in the constitutive equation can be attributed to identifiable, physically measurable quantities. The proposed model and its material constants give important information on how humidity and orientation influence the deformation behavior of PFSA membranes.

The proposed model demonstrates a good agreement with the experimental data at low strains. Furthermore, our test data show that PFSA exhibits an isotropic nonlinear response in the elastic regions with anisotropic hardening induced during plastic flow, similar to other semicrystalline polymers. PFSA does not exhibit strain softening but rather strain hardening at larger strains. This study also shows that the strain hardening behavior of the PFSA depends on the humidity and that the material hardens more with increasing humidity in the machine direction.

In order to use the proposed model to capture the mechanical behavior of other PSFA materials as well as other semicrystalline polymers, tests for these other materials must be conducted at a range of temperatures and humidities to determine the specific material constants for each. Also, the influence of high temperatures and humidities on the molecular relaxation and softening mechanisms should be investigated. Thus, further experimental and theoretical studies are required to understand the deformation mechanisms of PFSA membranes and the corresponding microstructural changes during the deformation in the presence of humidity.

In conclusion, the proposed constitutive model can be used to describe the uniaxial elastoplastic flow behavior of PFSA membranes within the given temperature-humidity range and can serve as a guide in developing a better understanding of the physical interaction of water with the microstructure of the polymer.

\section{Acknowledgment}

This research has been supported by grants from the U.S. Department of Energy, W.L. Gore \& Associates, Inc., and the State of Delaware Development Office. The Nafion ${ }^{\circledR}$ membranes used in the experiments were generously donated by DuPont. We also acknowledge the helpful discussions with Charles W. Martin of Gore and Associates regarding the morphology of PFSA.

\section{References}

[1] Beuscher, U., Cleghorn, S. J. C., and Johnson, W. B., 2005, "Challenges for PEM Fuel Cell Membranes," Int. J. Energy Res., 29, pp. 1103-1112.

[2] Cleghorn, S., Kolde, J., and Liu, W., 2003, "Catalyst Coated Composites Membranes," V. Wolf, L. Arnold, and G. Hubert, eds., Handbook of Fuel Cells: Fundamentals, Technology and Applications, Wiley, New York.

[3] Rajendran, R. G., 2005, "Polymer Electrolyte Membrane Technology for Fuel Cells,” MRS Bull., 30, pp. 587-590.
[4] Smitha, B., Sridhar, S., and Khan, A. A., 2005, "Solid Polymer Electrolyte Membranes for Fuel Cell Applications-A New Review," J. Membr. Sci., 259, pp. 10-26.

[5] Mauritz, K. A., and Moore, R. B., 2004, "State of Understanding of Nafion," Chem. Rev., 104, pp. 4535-4585.

[6] Gierke, T. D., Munn, G. E., and Wilson, F. C., 1981, "Morphology in Nafion Perfluorinated Membrane Products, as Determined by Wide- and Small-Angle X-Ray Studies,” J. Polym. Sci., Polym. Phys. Ed., 19, pp. 1687-1704.

[7] Kundu, S., Fowler, M. W., Simon, L. C., and Grot, S., 2006, "Morphological Features (Defects) in Fuel Cell Membrane Electrode Assemblies," J. Power Sources, 157, pp. 650-656.

[8] Crum, M., and Liu, W., 2006, "Effective Testing Matrix for Studying the Membrane Durability in PEM Fuel Cells: Part 2. Mechanical Durability and Combined Mechanical and Chemical Durability," Transactions 210 ECS Meeting, Cancun, Mexico, October 29-November 3, 2006.

[9] Liu, W., Ruth, K., and Rusch, G., 2001, "Membrane Durability in PEM Fuel Cells," J. New Mater. Electrochem. Syst., 4, pp. 227-232.

[10] Stanic, V., and Hoberecht, M., 2004, "Mechanism of Pin-Hole Formation in Membrane Electrode Assemblies for PEM Fuel Cells," Meeting of the Electrochemical Society, Honolulu, HI, 3-8 Oct. 2004, p. 1891.

[11] Xie, J., Wood, D. L., III, Wayne, D. M., Zawodzinski, T. A., Atanassov, P., and Borup, R. L., 2005, "Durability of PEFCs at High Humidity Conditions," J. Electrochem. Soc., 152, pp. 104-113.

[12] Kusoglu, A., Karlsson, A. M., Santare, M. H., Cleghorn, S., and Johnson, W. B., 2006, "Mechanical Response of Fuel Cell Membranes Subjected to a Hygro-thermal Cycle," J. Power Sources, 161, pp. 987-996.

[13] Kusoglu, A., Karlsson, A. M., Santare, M. H., Cleghorn, S., and Johnson, W. B., 2007, "Mechanical Behavior of Fuel Cell Membranes Under Humidity Cycles and Effect of Swelling Anisotropy on the Fatigue Stresses," J. Power Sources, 170, pp. 345-358.

[14] Tang, Y., Kusoglu, A., Karlsson, A. M., Santare, M. H., Cleghorn, S., and Johnson, W. B., 2008, "Mechanical Properties of a Reinforced Composite Polymer Electrolyte Membrane and Its Simulated Performance in PEM Fuel Cells," J. Power Sources, 175, pp. 817-825.

[15] Lai, Y.-H., Gittleman, C. S., Mittelsteadt, C. K., and Dillard, D. A., 2005 "Viscoelastic Stress Model and Mechanical Characterizaton of Perfluorosulfonic Acid, (PFSA) Polymer Electrolyte Membranes," Proceedings of the Third International Conference on Fuel Cell Science, Engineering, and Technology, Ypsilanti, MI, May 23-25, pp. 161-167.

[16] Tang, Y., Santare, M. H., Karlsson, A. M., Cleghorn, S., and Johnson, W. B. 2005, "Stresses in Proton Exchange Membranes Due to HydrahonDehydration Cycles," Proceedings of the Third International Conference on Fuel Cell Science, Engineering, and Technology, Ypsilanti, MI, May 23-25, pp. 207-213.

[17] Huang, X., Solasi, R., Zou, Y., Feshler, M., Reifsnider, K., Condit, D., Burlatsky, S., and Madden, T., 2006, "Mechanical Endurance of Polymer Electrolyte Membrane and PEM Fuel Cell Durability," J. Polym. Sci., Part B: Polym. Phys., 44, pp. 2346-2357.

[18] Solasi, R., Zou, Y., Huang, X., Reifsnider, K., and Condit, D., 2007, "On Mechanical Behavior and In-Plane Modeling of Constrained PEM Fuel Cell Membranes Subjected to Hydration and Temperature Cycles," J. Power Sources, 167, pp. 366-377.

[19] Curtin, D. E., Lousenberg, R. D., Henry, T. J., Tangeman, P. C., and Tisack, M. E., 2004, "Advanced Materials for Improved PEMFC Performance and Life," J. Power Sources, 131, pp. 41-48.

[20] Bergstrom, J. S., and Hilbert, L. B., Jr., 2005, "A Constitutive Model for Predicting the Large Deformation Thermochemical Behavior of Fluoropolymers," Mech. Mater., 37, pp. 899-913.

[21] Kletschkowski, T., Schomburg, U., and Bertram, A., 2002, "Endochronic Viscoplastic Material Models for Filled PTFE," Mech. Mater., 34, pp. 795-808.

[22] Khan, A., and Zhang, H. Y., 2001, "Finite Deformation of a Polymer: Experiments and Modeling," Int. J. Plast., 17, pp. 1167-1188.

[23] Tang, Y., Karlsson, A. M., Santare, M. H., Gilbert, M., Cleghorn, S., and Johnson, W. B., 2006, "An Experimental Investigation of Humidity and Temperature Effects on the Mechanical Properties of Perfluorosulfonic Acid Membrane," Mater. Sci. Eng., A, 425, pp. 297-304.

[24] Bauer, F., Denneler, S., and Willert-Porada, M., 2005, "Influence of Temperature and Humidity on the Mechanical Properties of Nafion ${ }^{\circledR} 117$ Polymer Elec trolyte Membrane," J. Polym. Sci., Part B: Polym. Phys., 43, pp. 786-795.

[25] Kundu, S., Simon, L. C., Fowler, M., and Grot, S., 2005, "Mechanical Properties of Nafion ${ }^{\circledR}$ Electrolyte Membranes Under Hydrated Conditions," Polymer, 46, pp. 11707-11715.

[26] Liu, D., Kyriakides, S., Case, S. W., Lesko, J. J., Li, Y. X., and McGrath, J. E. 2006, "Tensile Behavior of Nafion and Sulfonated Poly(Arylene Ether Sulfone) Copolymer Membranes and Its Morphological Correlations," J. Polym. Sci., Part B: Polym. Phys., 44, pp. 1453-1465.

[27] Kawano, Y., Wang, T., Palmer, R. A., and Aubuchon, S. R., 2002, "StressStrain Curves of Nafion Membranes in Acid and Salt Forms," Polímeros: Ciência e Tecnologia, 12, pp. 96-101.

[28] G'Sell, C., and Jonas, J. J., 1979, "Determination of the Plastic Behavior of Solid Polymers at Constant True Strain Rate,” J. Mater. Sci., 14, pp. 583-591.

[29] Duan, Y., Saigal, A., Greif, R., and Zimmerman, M. A., 2001, "A Uniform Phenomenological Constitutive Model for Glassy and Semicrystalline Polymers," Polym. Eng. Sci., 41, pp. 1322-1328.

[30] Malvern, L. E., 1969, Introduction to the Mechanics of a Continuous Medium, Prentice-Hall, Englewood Cliffs, NJ.

[31] Weber, A. Z., and Newman, J., 2004, "Transport in Polymer-Electrolyte Mem- 
branes: II. Mathematical Model,” J. Electrochem. Soc., 151, pp. 311-325.

[32] Jalani, N. H., Choi, P., and Datta, R., 2005, "TEOM: A Novel Technique for Investigating Sorption in Proton-Exchange Membranes," J. Membr. Sci., 254, pp. $31-38$

[33] van der Heijden, P. C., Rubatat, L., and Diat, O., 2004, "Orientation of Drawn Nafion at Molecular and Mesocopic Scales," Macromolecules, 37, pp. 53275336 .
[34] Gebel, G., and Diat, O., 2005, "Neutron and X-Ray Scattering: Suitable Tools for Studying Ionomer Membranes," Fuel Cells, 5, pp. 261-276.

[35] de Almeida, S. H., and Kawano, Y., 1999, "Thermal Behavior of Nafion Membranes," J. Therm Anal. Calorim., 58, pp. 569-577.

[36] Yeo, S. C., and Eisenberg, A., 1977, "Physical Properties and Supermolecular Structure of Perfluorinated Ion-Containing (Nafion) Polymers," J. Appl. Polym. Sci., 21, pp. 875-898. 